\title{
Animal Model
}

\section{Pathology of Interstitial Cells of Cajal in Relation to Inflammation Revealed by Ultrastructure But Not Immunohistochemistry}

\author{
Xuan-Yu Wang, ${ }^{*}$ Irene Berezin, ${ }^{*}$ \\ Hanne B. Mikkelsen, ${ }^{\dagger}$ Tara Der, ${ }^{*}$ Premysl Bercik, ${ }^{*}$ \\ Stephen M. Collins, ${ }^{*}$ and Jan D. Huizina* \\ From the Intestinal Disease Research Program and Department \\ of Medicine,* McMaster University, Hamilton, Ontario, Canada; \\ and the Institute of Medical Anatomy, ${ }^{\dagger}$ University of \\ Copenhagen, Copenhagen, Denmark
}

The role of interstitial cells of Cajal associated with Auerbach's plexus (ICC-AP) in the pathophysiology of inflammation-induced abnormalities in gut motor activity is poorly understood. Therefore we applied a well-described model of inflammation (infection by Trichinella spiralis) to the mouse small intestine where the structure and function of ICC-AP are best known. Electron microscopic evaluation revealed that 1 to 3 days after infection, selective and patchy damage to the ICC processes occurred, thereby disrupting contacts between these ICC and smooth muscle cells as well as ICC and nerves, which was associated with disordered electrical activity and abnormal peristalsis. Ten to 15 days after infection, damage to ICC-AP was maximal and now involving the cell body and major processes. Marked synthetic activity and regrowth of their processes occurred from day 3 onward and recovery was completed at day 40 after infection. No changes to the network of ICC-AP were seen with c-Kit immunohistochemistry. From day 1 after infection, macrophages infiltrated the AP area, making close contact including peg-and-socket-like junctions with smooth muscle cells and ICC-AP but up to day 6 after infection without any sign of phagocytosis. By day 6 after infection, lymphocytes entered the musculature forming close contacts with ICC-AP. This was not associated with damage to ICC-AP but with proliferation of rough endoplasmic reticulum. From day 23 onward, immune cells withdrew from the musculature except macrophages, resulting in a markedly increased population of macrophages in the AP area at day 60 after infection. (Am J Pathol 2002, 160:1529-1540)
Our understanding of the role of interstitial cells of Cajal (ICC) in the pathophysiology of intestinal motor disorders related to inflammation is hampered by our limited knowledge of effects of inflammation on this cell system. Therefore, a well-described model of inflammation (infection with $T$. spiralis) was applied to the mouse small intestine where the structure and function of ICC are best known.

ICC associated with Auerbach's plexus (ICC-AP) in the small intestine perform a pacemaker function for intestinal motor activity. ${ }^{1,2}$ ICC-AP are associated with slowwave-driven peristalsis, which is prominent during gastric emptying and small bowel transit. ${ }^{3}$ In fact, normal peristaltic activity in the small bowel after gastric emptying of a liquid was absent in $W W^{\vee}$ mutant mice that do not have ICC-AP. ${ }^{3}$ ICC-AP are characterized by elongated cell bodies with extremely long, thin, ramified cell processes interconnected by close apposition contacts and gap junctions. ICC-AP have many ultrastructural features in common with smooth muscle cells and fibroblasts, but can be identified because of a unique combination of ultrastructural features together with unique structural associations with nerves and smooth muscle cells. ${ }^{4-6}$

ICC harbor the c-Kit protein and can therefore be identified at the light microscopy level using immunohistochemistry with c-Kit antibodies., ${ }^{2,7}$ In fact, almost all current studies on the pathology of ICC are performed by immunostaining. ${ }^{8,9}$ By using both electron microscopy (EM) and immunohistochemistry we discovered in the present study that marked changes in ICC at the EM level, associated with previously observed functional changes, ${ }^{10}$ did not lead to any changes at the light microscopy level using Kit immunohistochemistry.

Supported by grants from the Canadian Institutes of Health Research and a Canadian Association of Gastroenterologists fellowship from JanssenOrtho (to X.-Y. Wang).

Accepted for publication January 9, 2002

Address reprint requests to Dr. Jan D. Huizinga, McMaster University, HSC-3N5C, 1200 Main St. West, Hamilton, ON L8N 3Z5, Canada. E-mail: huizinga@mcmaster.ca. 
The mouse small intestine harbors resident macrophages that have a close structural relationship with ICC. ${ }^{11}$ It was therefore of interest to follow the interaction between macrophages and ICC-AP during and after the inflammatory process.

\section{Materials and Methods}

\section{Animals}

Specific pathogen-free, male, 5- to 7-week-old, C57BL/6 mice (Taconic Farms, Germantown, NY) maintained in sterilized filtered cages were inoculated with 375 to 500 $T$. spiralis larvae using the procedures previously described by Castro and Fairbairn ${ }^{12}$ and modified by Vermillion and Collins. ${ }^{13}$ All of the experiments were approved by the McMaster University Animal Care Committee and the Canadian Council on Animal Care.

\section{Electron Microscopy}

EM was performed on tissue from non-infected control mice $(n=7)$, and mice infected with $T$. spiralis 24 hours $(n=12), 48$ hours $(n=12), 3$ days $(n=8), 6$ days $(n=$ $6), 8$ days $(n=6), 15$ to 17 days $(n=8), 21$ to 23 days $(n=4), 40$ days $(n=4)$, and 60 days $(n=3)$ previously. Under terminal anesthesia with Fluothane (Ayerst, Montreal, Canada), a fixative solution containing $2 \%$ glutaraldehyde, $0.075 \mathrm{~mol} / \mathrm{L}$ sodium cacodylate buffer, $\mathrm{pH} 7.4$, $4.5 \%$ sucrose, and $1 \mathrm{mmol} / \mathrm{L} \mathrm{CaCl}_{2}$, was gently injected into the peritoneal cavity as well as the lumen of the proximal $10 \mathrm{~cm}$ of the small intestine already tied at both ends. After 5 minutes of initial fixation, the proximal $8-\mathrm{cm}$ segment of jejunum beginning 1-cm distal to the pylorus, was removed, opened lengthwise, and placed in the same fixative for an additional 2 hours at room temperature. After fixation, the tissues were cut into $2 \times 5-\mathrm{mm}$ circular and longitudinal strips, washed overnight in 0.1 $\mathrm{mol} / \mathrm{L}$ sodium cacodylate buffer containing $6 \%$ sucrose and $1.24 \mathrm{mmol} / \mathrm{L} \mathrm{CaCl} 2(\mathrm{pH} 7.4)$ at $4^{\circ} \mathrm{C}$, postfixed with $1 \%$ $\mathrm{OsO}_{4}$ in $0.05 \mathrm{~mol} / \mathrm{L}$ sodium cacodylate buffer $(\mathrm{pH} 7.4)$ at room temperature for 90 minutes, stained with saturated uranyl acetate for 60 minutes at room temperature, dehydrated in graded ethanol and propylene oxide, and embedded in Spurr. Tissue strips were oriented in molds to cut the circular muscle (CM) layer in either the cross or longitudinal direction. To locate suitable areas, $0.5-\mathrm{mm}$ thick sections were cut and stained with $2 \%$ toluidine blue. After examination of the toluidine blue-stained sections, ultrathin sections were cut, mounted on 200-mesh grids, and stained with lead citrate. The grids were examined in a Jeol-1200 EX Biosystem electron microscope at $80 \mathrm{kV}$.

This study focuses on changes in ICC-AP that are involved in gut pacemaker activity, it does not discuss the other types of ICC. The nomenclature conforms to that of Faussone-Pellegrini and Thuneberg ${ }^{6}$ and Komuro. ${ }^{14}$

\section{Immunohistochemistry for ICC-AP}

Whole mounts were made from the musculature of the proximal jejunum (1- to $8-\mathrm{cm}$ distal from the pylorus) from T. spiralis-infected and control mice. Tissues were processed from control mice $(n=6)$, day $1(n=4)$, day 2 $(n=4)$, day $15(n=6)$, day $40(n=3)$, and day $60(n=$ 3) after infection. All whole-mount preparations were fixed in ice-cold acetone at $4^{\circ} \mathrm{C}$ for 10 minutes. After fixation, preparations were incubated with $1 \%$ bovine serum albumin for 1 hour to reduce the nonspecific staining before addition of the primary antibody rat monoclonal anti-c-Kit (ACK2, 1:200; Life Technologies, Inc., Gaithersburg, MD). After the incubation with primary antibody for 2 nights at $4^{\circ} \mathrm{C}$, fluorescein isothiocyanate-coupled rabbit anti-rat IgG (Vector Laboratories, Burlingame, CA) was added to the tissue with a dilution of 1:100 and left for 1 hour. Tissues were examined with a confocal microscope (LSM 510; Zeiss, Germany) with an excitation wavelength appropriate for fluorescein isothiocyanate (494 nm). Final images were constructed with Carl Zeiss software. Control tissues were prepared by omitting primary antibody from the incubation solution. All of the antibodies were diluted with $0.05 \mathrm{~mol} / \mathrm{L}$ phosphate-buffered saline with $0.3 \%$ Triton $\mathrm{X}-100$.

\section{Immunohistochemistry for Macrophages}

Proximal jejunum was removed from both infected and control mice as described above. Tissues from each animal were divided into two groups, one for wholemount preparations and another for frozen sections. Muscle whole mounts were made by peeling away the mucosa and submucosa. To prepare frozen sections, after freezing the mouse intestine in isopentane and liquid nitrogen, sections of $5 \mu \mathrm{m}$ were cut with the cryostat, both whole mounts and frozen sections were fixed in ice-cold acetone for 5 minutes, and then fixed with ice-cold $3.75 \%$ periodate-lysine-paraformaldehyde for 10 minutes at $4^{\circ} \mathrm{C}$ immediately before the immunostaining. Endogenous peroxidase was quenched by submerging the tissues in $1 \%$ hydrogen peroxide for 15 minutes and nonspecific antibody binding was blocked by the incubation with $8 \%$ normal goat serum plus 1\% bovine serum albumin for 1 hour. The tissues were then incubated with monoclonal rat anti-mouse F4/80 (diluted to 1:15 with 8\% normal goat serum and $1 \%$ bovine serum albumin; Serotec, Oxford, UK) overnight at $4^{\circ} \mathrm{C}$ plus 1 hour at room temperature. Biotinylated rabbit anti-rat IgG (mouse adsorbed; DAKO, Glostrup, Denmark) was added to the tissues at a 1:400 dilution (diluted with $1 \%$ bovine serum albumin) and left for 1 hour at room temperature. After incubating the tissues with ABC-complex (Vector Laboratories) for 1 hour, $3,3^{\prime}$ diaminobenzidine $\left(0.05 \%\right.$ DAB plus $0.01 \% \mathrm{H}_{2} \mathrm{O}_{2}$ in $0.05 \mathrm{~mol} / \mathrm{L}$ Tris buffer saline, $\mathrm{pH}$ 7.6) was used as peroxidase substrate. Frozen sections were then counterstained with Mayer's hematoxylin and pictures were taken with the digital camera (Sony 3CCD, model no. DXC-930; Sony, Japan). For whole-mount preparations, pictures were taken focused on the level of AP. Because 


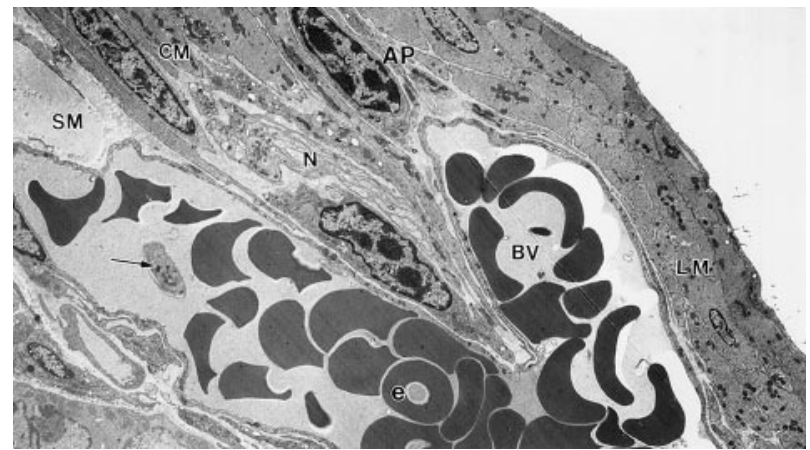

Figure 1. A mucosal Trichinella spiralis infection has an immediate response in the musculature. By day 1 after infection, blood vessels in the musculature were greatly dilated and filled with erythrocytes and platelets. Enlarged blood vessels (bv) with platelets (arrow) and numerous erythrocytes (e) extended from the submucosa (SM), through the CM septum, into the AP region. $\mathrm{N}$, nerve bundle. Original magnification, $\times 3840$.

of the very thin longitudinal muscle (LM) layer, F4/80 immunoreactivity in the serosa was inevitably present in the picture. Control experiments involved incubation of the sections with a rat $\lg _{2 b}$ isotypic control (Serotec) instead of anti-F4/80 serum.

Quantification of $\mathrm{F} 4 / 80$ positivity was performed on a G3 Macintosh computer using the public domain $\mathrm{NIH}$ Image 1.62 program (developed at the National Institutes of Health and available on the Internet at $h t t p: / / r s b$.info. nih.gov/nih-image/). F4/80-immunopositive cells were identified and highlighted using density slicing on gray scale images. The area of immunopositive cells was calculated and then expressed as percentage of total area of the image. Regions with increased background staining, occasionally found at the borders of the image, were excluded from the analysis.

\section{Results}

As early as 24 hours after infection, T. spiralis was observed within the mucosa but was never seen to penetrate beyond the lamina propria. Nevertheless, at this time changes were already occurring in the musculature: all blood vessels within the AP region were dilated and filled with erythrocytes and platelets (Figure 1).

\section{Immunohistochemistry of ICC}

ICC-AP were seen as c-Kit-positive multipolar cells connected to each other by long processes to form a meshlike structure associated with AP (Figure 2a). This structural arrangement remained essentially unaltered during and after the mucosal infection (Figure 2b, day 15 after infection).

\section{Immunohistochemistry of Macrophages Using F4/80}

Resident macrophages were present primarily in the subserosal space as well as in the AP region but not within the muscle layers as observed in whole-mount muscle preparations from pathogen-free control mice (Figure 3a and Figure 4a). There was no variability in the distribution of macrophages in control mice. After 24 hours of infection, macrophages infiltrated the AP region (see EM results) and after 48 hours of infection macrophages were present in both muscle layers (not shown). Figures 3b and $4 \mathrm{~b}$ show the dramatic increase in $\mathrm{F} 4 / 80$-positive cells at day 15 after infection. A high concentration was found in the AP region but they were also scattered throughout the muscle layers and at the level of the deep
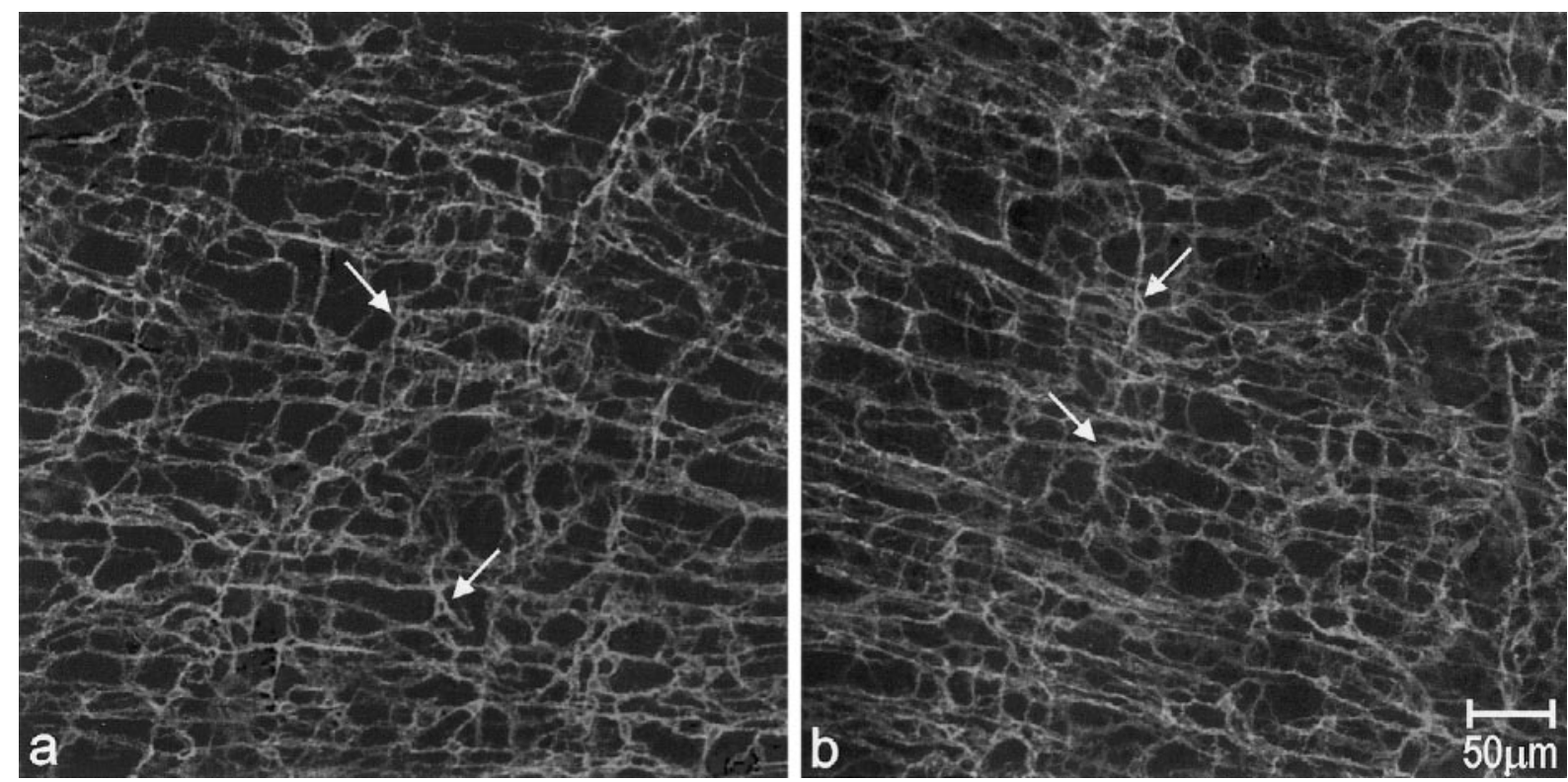

Figure 2. Whole-mount preparations showing Kit immunoreactivity in control and tissue day 15 after infection tissue. In control tissue (a), most of the c-Kit-positive cells (arrows) were multipolar-shaped, with several processes protruding in different directions and contacting each other to form highly branching networks at the level of AP. Compared with control tissue, animal tissues at day 15 after infection showed similar c-Kit immunoreactivity (b, arrows show the c-Kit-positive cells). 

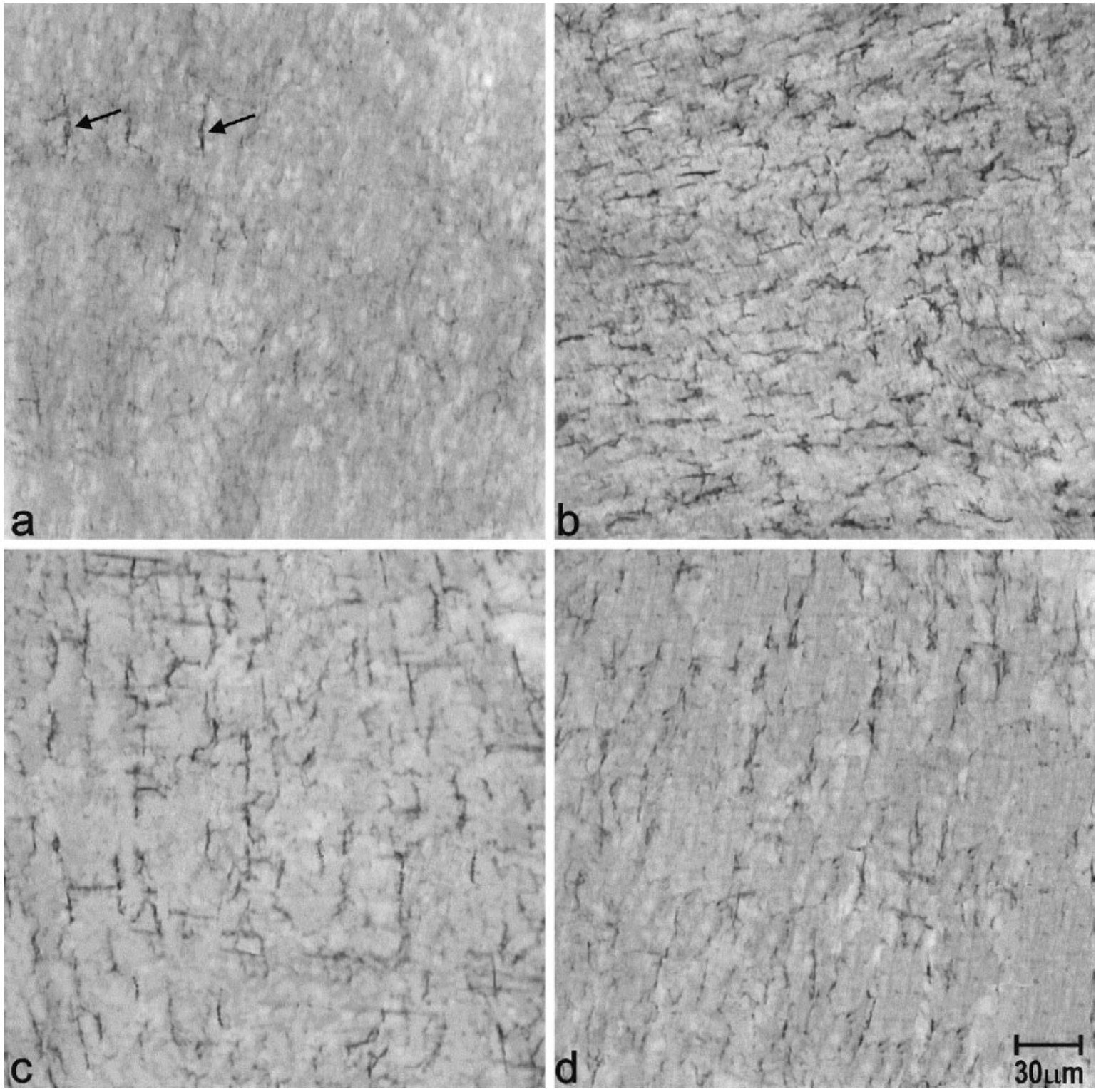

Figure 3. Whole-mount immunostaining of macrophages with F4/80 antibodies. F4/80 immunoreactivity in the muscle layers of the jejunum of control (a), and at day 15 (b), 40 (c), and 60 (d) after infection. There was comparatively little F4/80 in control tissue. Arrows show the F4/80-positive cells. By day 15 after infection, the number of F4/80-positive cells was markedly increased throughout the musculature. At days 40 and 60 after infection, the number of macrophages were reduced but were still higher than in control tissue.

muscular plexus. After 23 days, the number of macrophages gradually decreased although even at day 40 , there still was a marked increase greater than control values (Figures $3 \mathrm{c}$ and $4 \mathrm{c}$ ). At day 60 after infection, the number of macrophages in the AP region was still markedly increased and macrophages within the muscle layers could still be found (Figures 3d and 4d). Quantitatively, F4/80 immunoreactivity occupied $1.1 \pm 0.4 \%$ of total area $(n=4)$ in control tissue, on day 15 after infection this was $7.7 \pm 1.0 \%(n=4)(P<0.0001)$, on day 40 after infection it was $5.8 \pm 0.7 \%(n=3)(P<$ $0.0001)$, and on day 60 after infection it was $5.1 \pm 0.8 \%$ $(n=3)(P<0.003)$. Immunoreactivity on day 40 after infection was significantly reduced compared to day 15 after infection, there was no significant difference between days 40 and 60 after infection.

\section{Ultrastructure of ICC-AP}

Injury to ICC was extremely rare in tissue from properly fixed control mice that were processed in the same manner and at the same time as tissue from infected mice. Furthermore, in inflamed tissue, many ICC-AP not associated with blood vessels did not show any structural abnormalities, ruling out fixation artifacts. ICC were identified as described by Thuneberg. ${ }^{4}$ A key feature was the presence of caveoli. Throughout the cytoplasm of the cell body and processes, intermediate and thin filaments were present but thick filaments were absent. Lysosomes were rarely observed. Rough endoplasmic reticulum ( $r E R$ ) was found to be sparse in all regions of the ICC, and Golgi complexes were observed only in the perinuclear region, hence not in the processes. 

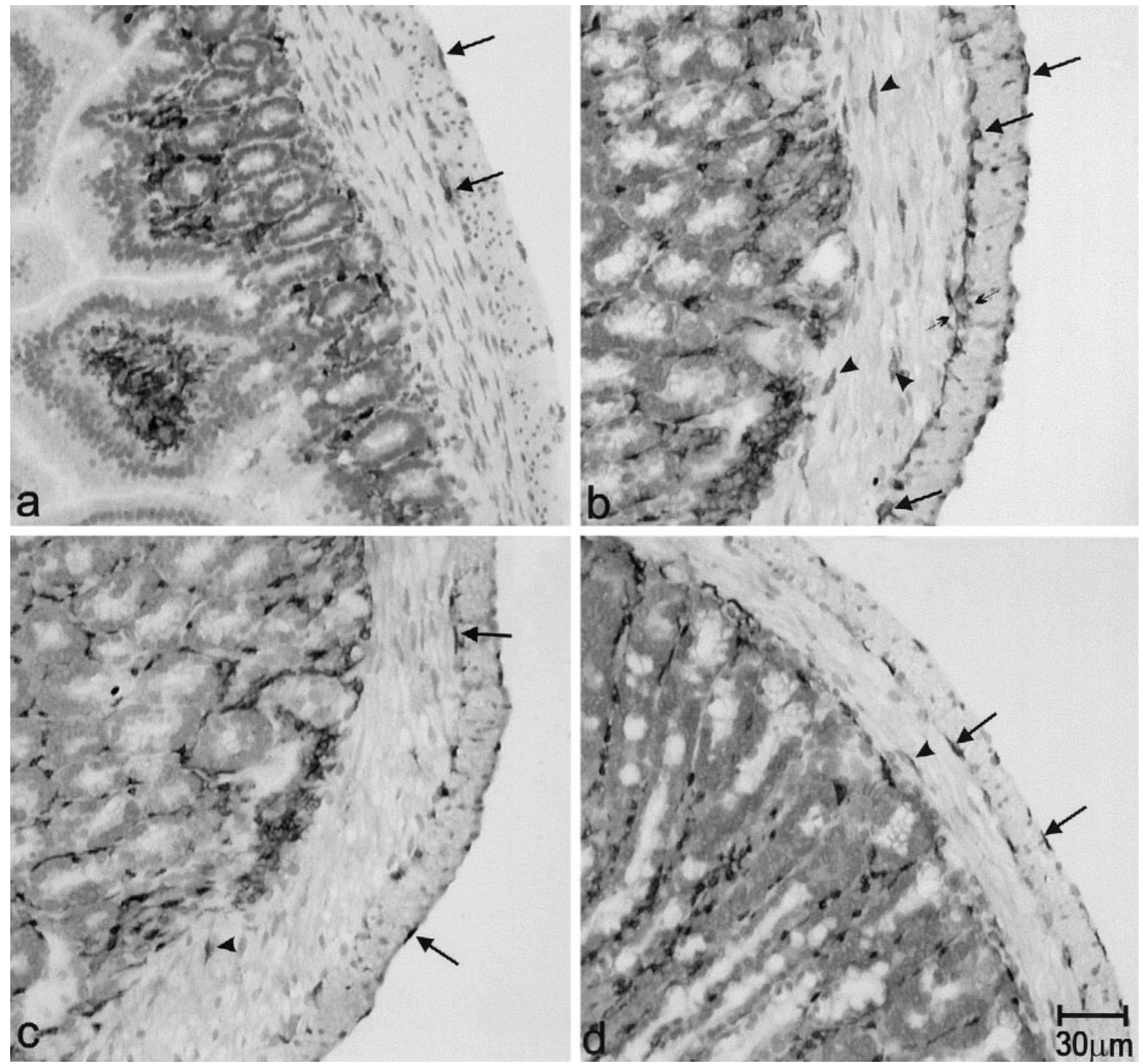

Figure 4. Immunostaining of macrophages with F4/80 antibodies, transverse sections, immunostained with F4/80, in control tissue (a), and at days 15 (b), 40 (c), and 60 (d) after infection. In control tissue, F4/80-positive cells were seen at the level of the serosa and AP (arrows). There was no immunoreactivity found within both muscle layers or at the deep muscle plexus (DMP) level. b: At day 15 after infection F4/80 immunoreactivity was significantly increased at the levels of both the serosa and AP (arrows). Some immunoreactive cells contacted each other (small arrows) to form a continuous dark line at the AP level. Moreover, F4/80-positive cells appeared within the CM layer and at the DMP level (arrowheads). c and d: At days 40 and 60 after infection, F4/80-IR cells in the muscle layers decreased compared with day 15 after infection, but still were markedly enhanced in number compared to control tissue. Arrows indicate the F4/80-immunoreactive cells in the serosa and AP. There is still F4/80 immunoreactivity in the CM layers of tissues at days 40 and 60 after infection (arrowheads).

From days 1 to 3 after infection, ICC-AP displayed ultrastructural abnormalities primarily restricted to their processes without involvement of the nucleus and perinuclear space (Figure 5, a and b). Loss of the intermediate filament network was observed, as well as a partial depletion of thin filaments (Figure 5a). Small lysosomes were present (Figure 5a) and multiple membrane structures formed as a result of membrane ruptures (Figure $5 b)$. Many terminal processes were ruptured with complete loss of their cytoplasmic contents (Figure 5b). These changes were seen in a patchy manner throughout the tissue but were primarily associated with those ICC-AP closest to dilated blood vessels, which were mainly confined to the AP region (Figures 6, 7, and 8).

Between 6 to 23 days after infection, ICC-AP injury also involved the larger processes and the perinuclear re- gions (Figure 5, c and d; and Figure 6, a to f), but injury was restricted to the membrane and filament structures. Injury to nuclei was minimal. Multiple membrane structures and plasma membrane blebs were displayed in the cytoplasm and associated with the plasma membrane (Figure 5c; Figure 6, b to f; Figure 7b; and Figure 8, b and c). In some perinuclear regions, cytoplasmic content was partially lost (Figure 5d). Nonetheless, injury to ICC-AP never involved the whole ICC-AP network (see Figure $2 \mathrm{~b}$ ), and in many sections, ICC-AP and their processes were not damaged (Figure $5 \mathrm{c}$ ). Injury was again most prevalent close to dilated blood vessels in the AP (Figures $6 a, 7 a$, and $8 \mathrm{a})$.

ICC with damaged processes did not make close contact with smooth muscle cells or nerve varicosities, features always present in undamaged ICC. Damage was 
1534 Wang et al

AJP April 2002, Vol. 160, No. 4
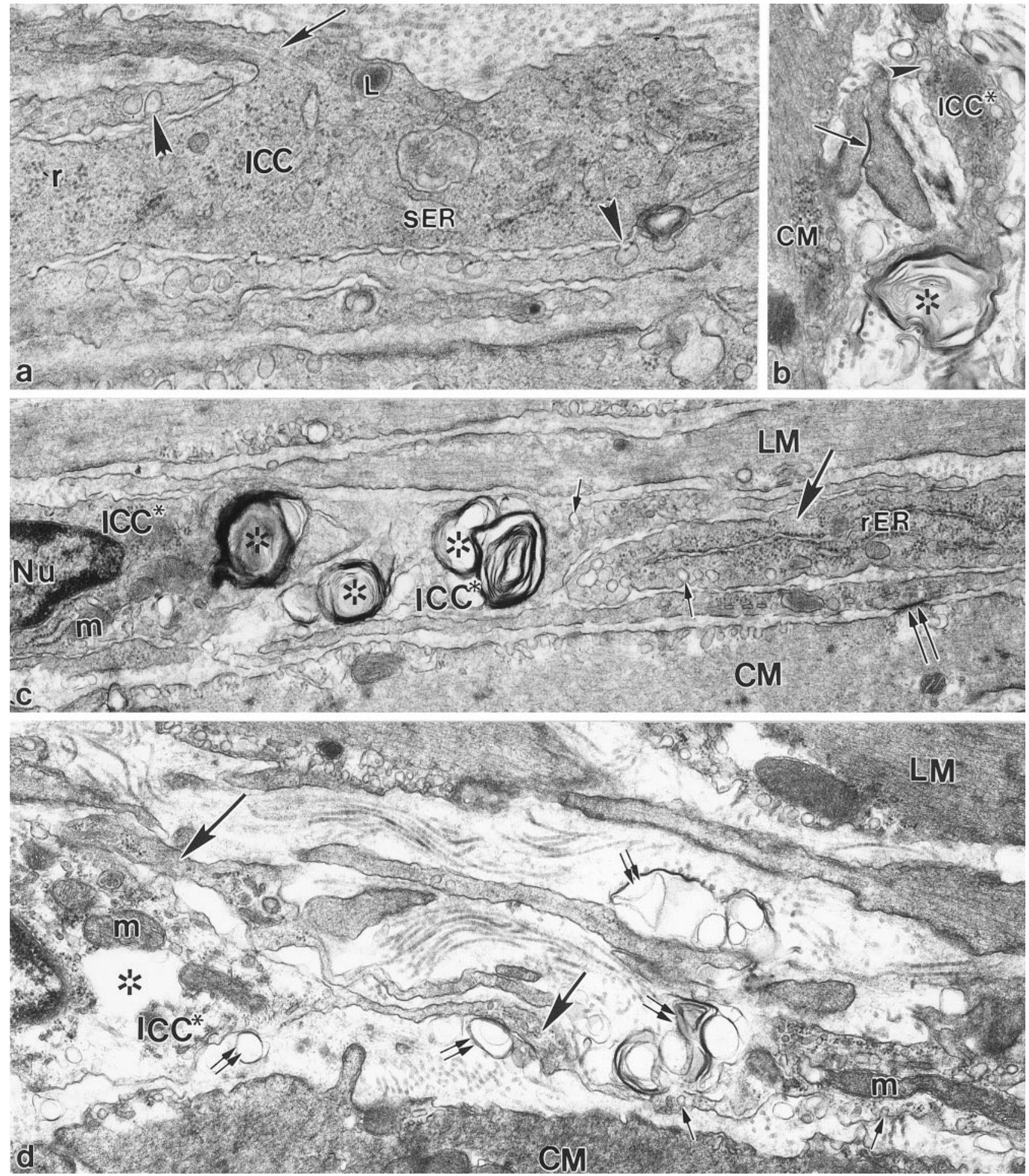

Figure 5. Ultrastructural pathology of ICC-AP at 1 to 23 days after infection. a: Two days after infection, a severely injured ICC-AP process was characterized by loss of almost all intermediate filaments. The remaining intermediate filaments could be seen only at the point of ramification of ICC-AP processes (arrow). The rest of the ICC-AP cytoplasm contained only thin filaments, free ribosomes (r), lysosomes (L), and a few cisternae of smooth endoplasmic reticulum (sER). Arrowheads indicate caveolae. b: Two days after infection, a degenerating terminal segment of an ICC-AP process (ICC*) formed a multiple membrane structure (asterisks) without any cytoplasmic content. The injured ICC* process could still be distinguished by the presence of surface caveolae (arrowhead). The arrow indicates a gap junction contact between CM projections. c: Eight days after infection, ICC cell bodies (ICC*) as well as ICC processes (ICC*) displayed multiple membrane structures (asterisks) in their cytoplasm. No obvious changes were seen in the mitochondria (m) and nucleus (Nu). The undamaged ICC process (large arrow) on the right was characterized by the presence of prominent rER. Small arrows indicate ICC caveolae. Double arrows show close contact between a CM cell and an ICC process. d: Twenty-three days after infection an injured ICC cell body (ICC*) and a group of adjacent injured processes (large arrows) at the level of $\mathrm{AP}$ were seen. The swollen and injured ICC perinuclear region was characterized by partial loss of cytoplasmic content (asterisks), and the presence of plasma membrane blebs (double arrows), a result of partial disintegration of the plasma membrane. No apparent structural abnormality was seen in mitochondria (m) in the ICC cytoplasm. The damaged ICC processes displayed similar structural signs of injury: dismantling and loss of many filaments and the presence of many plasma membrane blebs (double arrows). ICC processes were recognized by the presence of surface caveolae (small arrows). Original magnifications: $\times 32,200(\mathbf{a}) ; \times 22,100(\mathbf{b}) ; \times 21,375(\mathbf{c}) ; \times 23,750(\mathbf{d})$ 

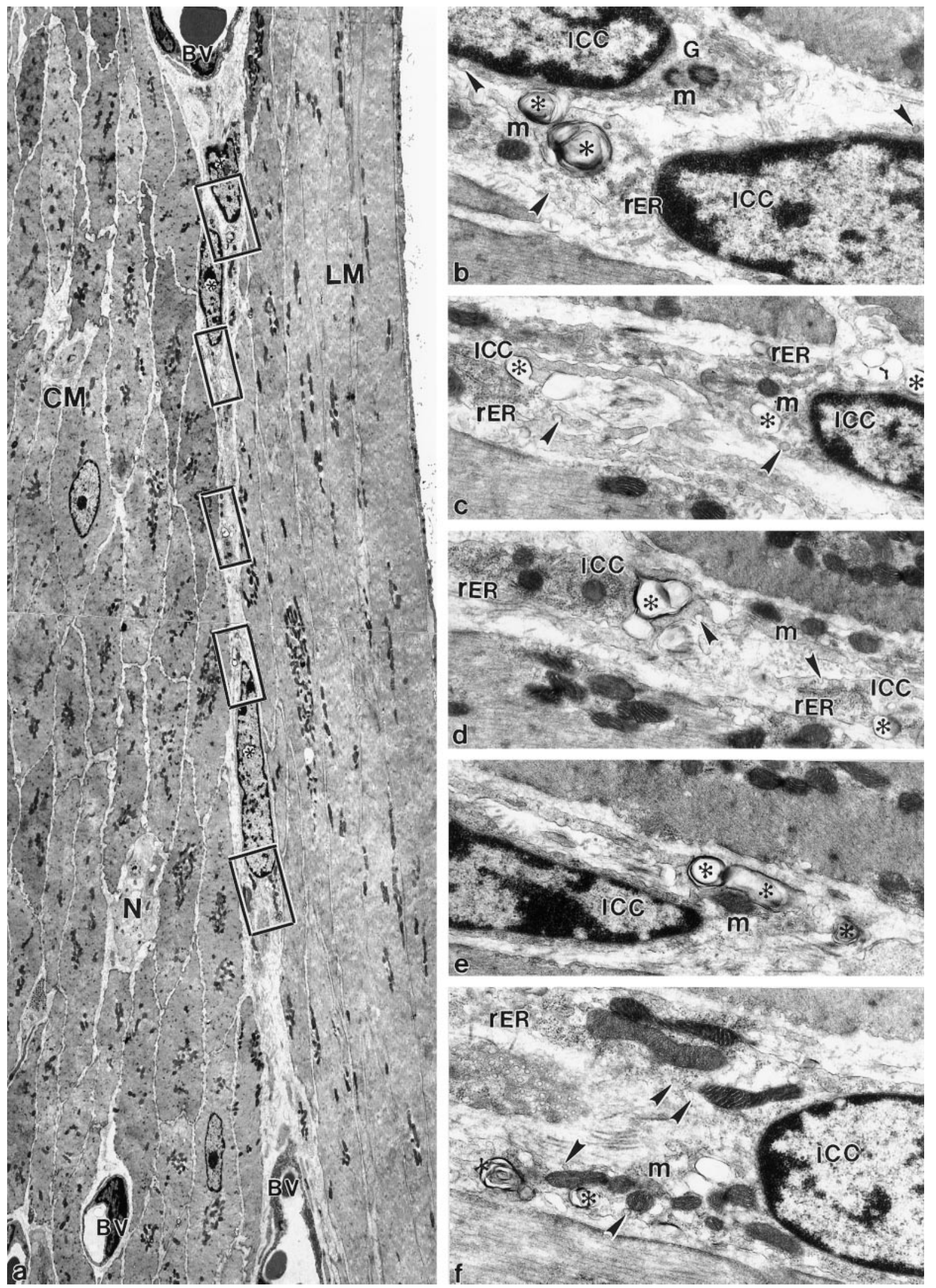

Figure 6. Eight days after infection injury resulting from the mucosal infection is limited to the ICC-AP and does not substantially affect smooth muscle. a: Low magnification to show both muscle layers surrounding AP. Three ICC-APs (asterisks) with relatively large nuclei and scarce cytoplasm were seen between two enlarged blood vessels (BV) in the AP area. N, nerve fibers. Squares: Local and selective injuries at the level of AP. b-f: Enlargement of squared areas in a. All of the injuries were limited to either the perinuclear areas or the processes of ICC-AP (ICC) with the presence of multiple membrane structures and plasma membrane blebs (asterisks). G, Golgi cisternae; m, mitochondria. Arrowheads, caveoli. Original magnifications: $\times 3150(\mathbf{a}) ; \times 18,330$ (b-f). 

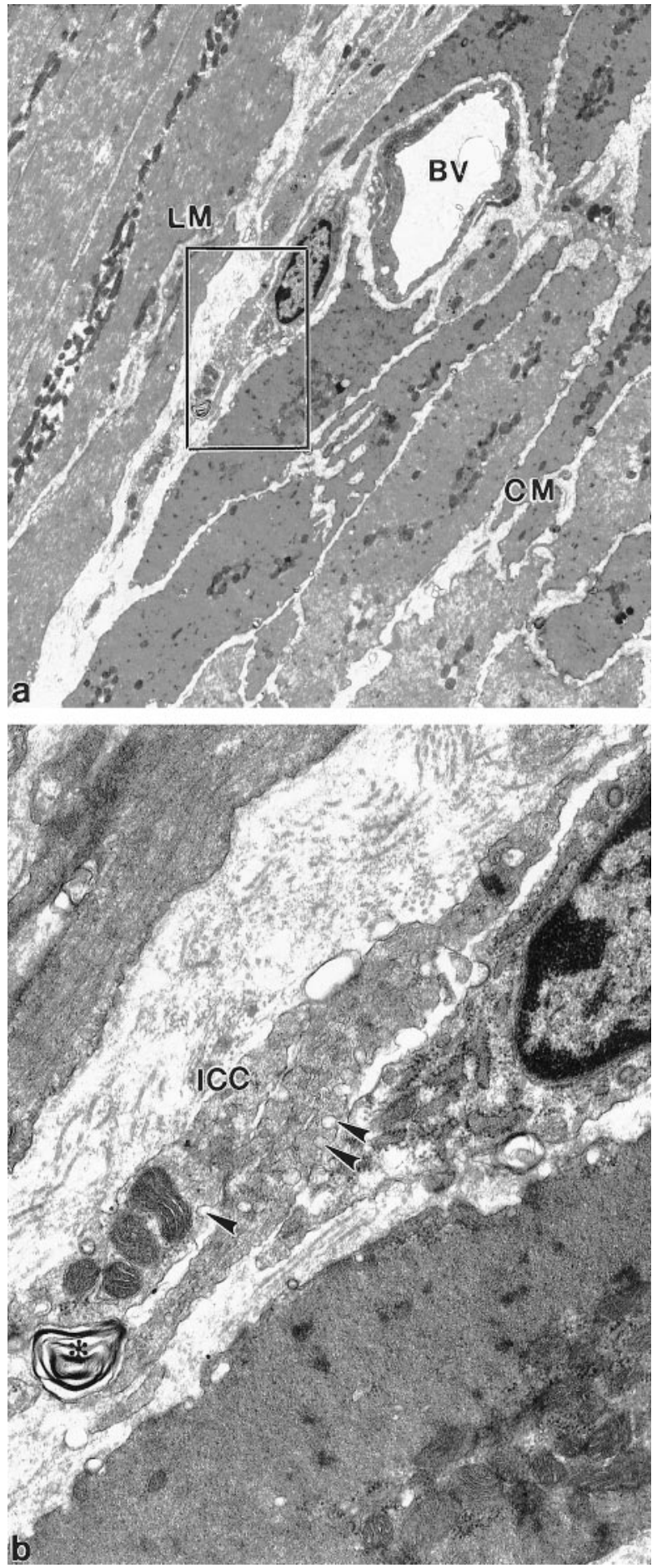

Figure 7. At 8 days after infection injury to ICC processes is not associated with smooth muscle injury. a: Low magnification identifies both muscle layers and ICC associated with a blood vessel. Injury is difficult to characterize at this magnification and sections at this magnification are not easily distinguished from control tissue. BV, blood vessel. b: Enlargement of the squared area in a. Multiple membrane structures (asterisk) are present associated with two ICC processes (ICC). Arrowheads: caveoli. Original magnifications: $\times 5210(\mathbf{a}) ; \times 25,000(\mathbf{b})$.

primarily restricted to ICC, most smooth muscle cells were not injured (Figures 6 to 8).

From day 3 onward, injury to ICC-AP was concurrent with extensive proliferation of ribosomes, rER, and Golgi
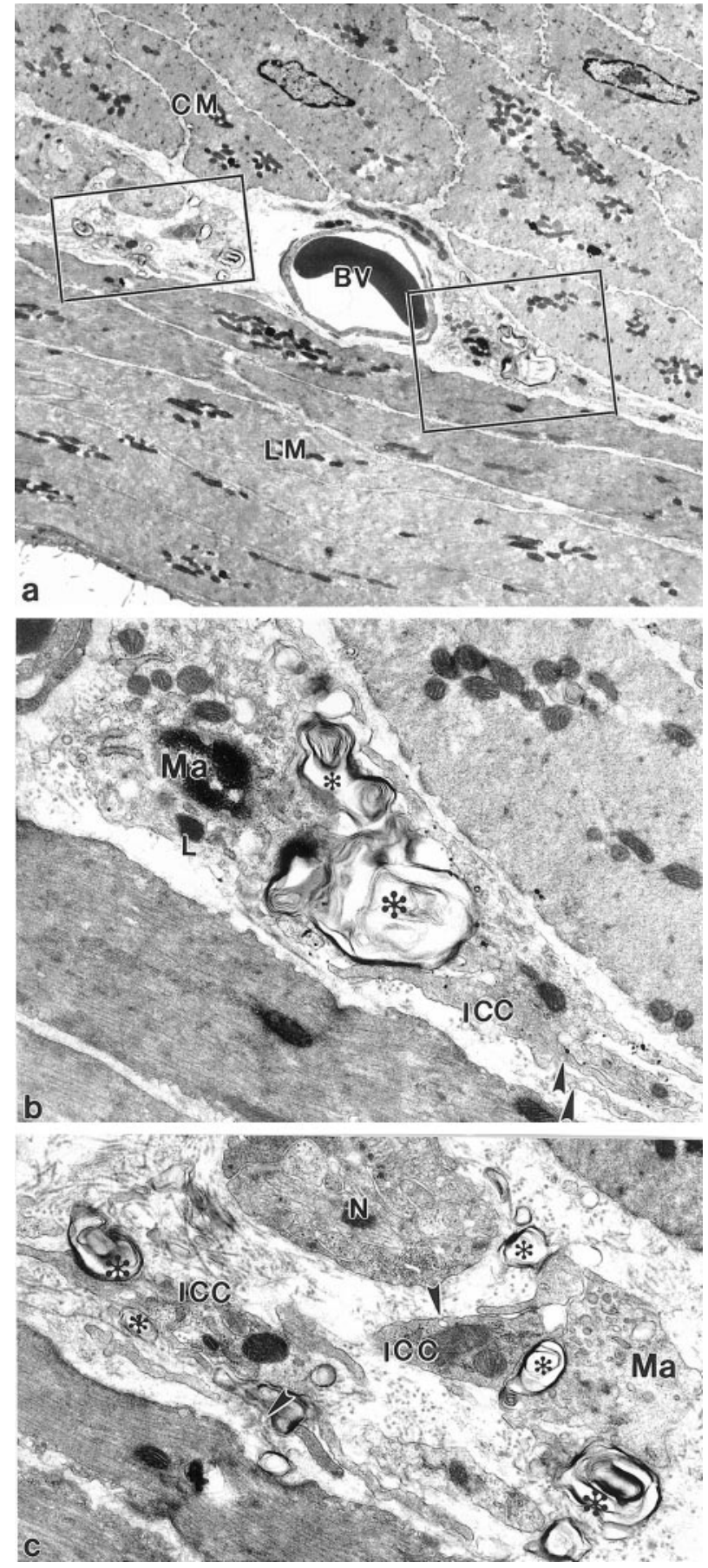

Figure 8. At 15 days after infection the injured ICC closely contact with the macrophages in the AP. a: Low magnification to show ICC and surrounding smooth muscle cells. BV, blood vessel. Squares: Degenerated structures at the level of AP. b and c: Enlarged pictures from the squared areas in a Macrophages (Ma) make close contact with the damaged ICC processes (ICC) in the AP region. The injured processes are characterized by the appearance of multiple membrane structures and plasma membrane blebs (asterisks). L, lysosome; N, nerve fibers. Arrowheads: caveoli. Original magnifications: $\times 4250(\mathbf{a}) ; \times 18,000(\mathbf{b}$ and $\mathbf{c})$.

complexes in many ICC-AP (Figure 9; a to c). In noninfected mice, rER was sparse in all regions of ICC-AP, and Golgi complexes were observed only in the perinuclear regions, and were not apparent in the processes. In infected mice, outgrowth and expansion of rER and Golgi 


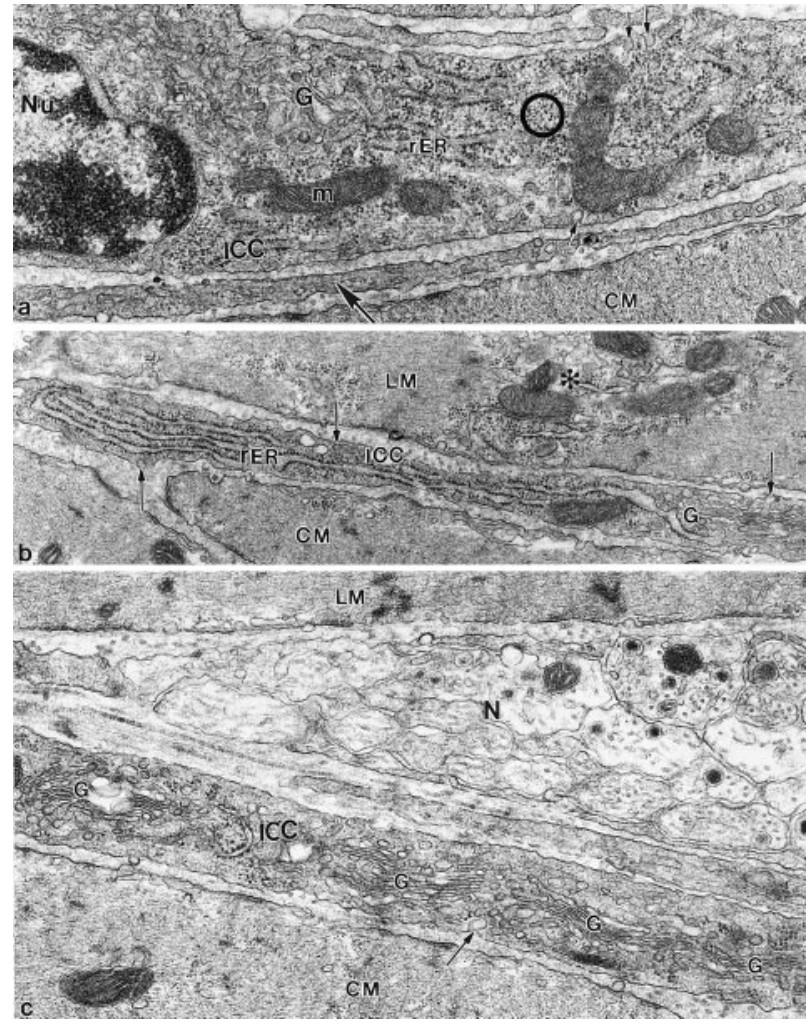

Figure 9. Increase of synthetic activity. a: At 6 days after infection the nucleated part of ICC displayed numerous cisternae of rER and ribosomes (circle), structural evidence of pronounced synthetic activity. No signs of cellular injury were seen in ICC-AP and ICC-AP processes (large arrow). The ICC-AP was distinguished from fibroblasts and macrophages by the presence of surface caveolae (small arrows). Nu, nucleus; $\mathrm{m}$, mitochondrion; b: At 8 days after infection a terminal ICC-AP process recognized by the presence of caveoli (arrows), showed conspicuous outgrowth of rER. The adjacent LM showed structural evidence of moderate cellular injury: a pale cytoplasm (asterisk) because of partially dismantled myofilaments. The right part of the process contains Golgi complexes $(G)$ and caveoli, which distinguishes it from a fibroblast. Original magnifications: $\times 34,760$ (a); $\times 26,670(\mathbf{b})$

complexes was present not only in perinuclear regions (Figure 9a), but also in the cell processes (Figure 9, b and c) resulting in a partial shifting of filaments from the central cytoplasm to the periphery. At 40 days after infection, the majority of ICC-AP processes were structurally similar to control. Injured ICC-AP processes were extremely rare on day 60 after infection but some ICC-AP continued to display proliferation of $\mathrm{rER}$ and ribosomes in their cytoplasm.

\section{Ultrastructural Relationships between ICC-AP, Smooth Muscle Cells, and Immune Cells}

Within the muscle layers and around the AP area, injury to smooth muscle cells was rare and severe injury did not occur. Except for resident macrophages, ${ }^{15}$ immune cells were not present in non-infected specific pathogen-free control mice. As early as 24 hours after infection, conspicuously activated macrophages were seen in the AP region in extensive close contact with ICC-AP processes (Figure 8, a to c; Figure 10, a to c). Activated macrophages were enlarged, with numerous cytoplasmic fold-
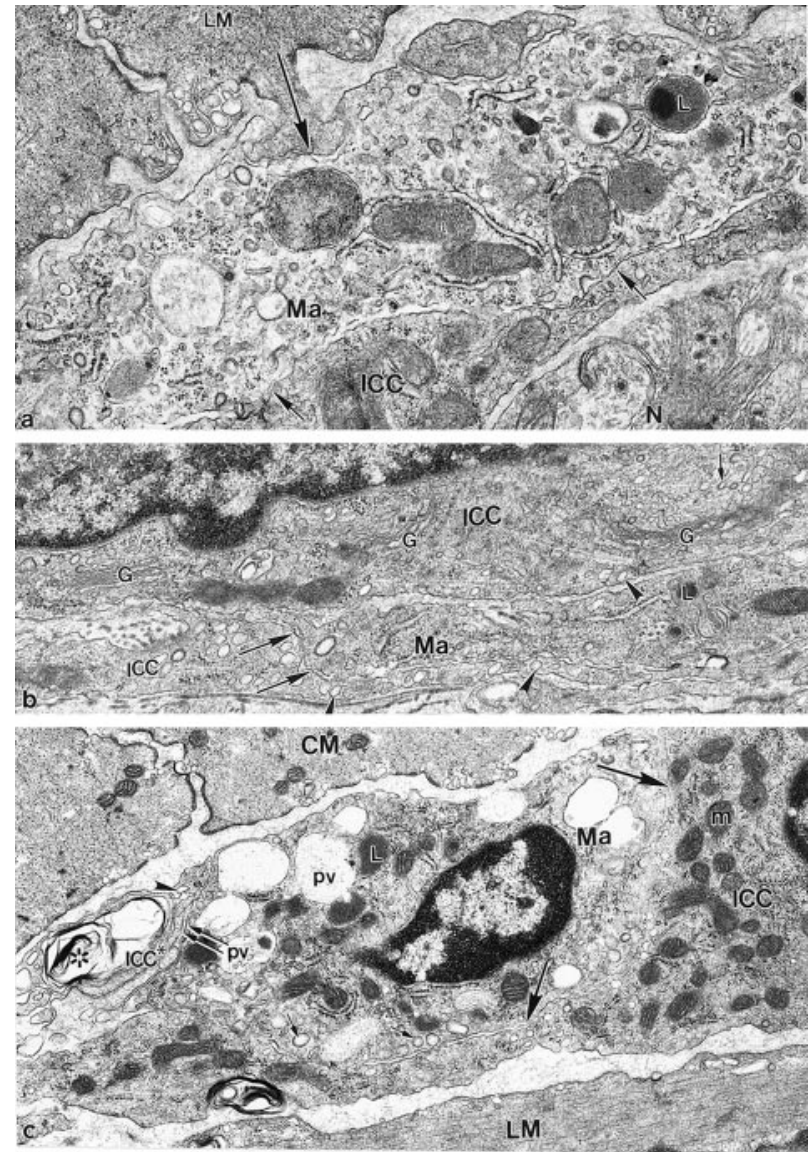

Figure 10. Association between macrophages and ICC-AP. a: At 2 days after infection a peg-and-socket junction-like contact (large arrow) between a macrophage process ( $\mathrm{Ma}$ ) and a LM indicates the possibility of functional interaction between immune cells and smooth muscle cells. Note additional close apposition contacts (small arrows) between macrophage and an adjacent ICC-AP process. N, tertiary nerve situated in close proximity to ICC-AP process; L, secondary lysosome. b: At 3 days after infection an ICC-AP situated in close proximity to an activated macrophage process (Ma) is seen. The perinuclear region of ICC-AP displayed multiple Golgi complexes (G) and many transport vesicles (small arrows). No prominent signs of cell injury were seen in the perinuclear space. Note the close relationship (large arrows) between a macrophage process and the ICC-AP process. ICC-APs were distinguished from the macrophage by the presence of caveolae (arrowheads). L, lysosome. c: At 15 days after infection a macrophage (Ma) containing numerous phagocytic vacuoles (pv), large lysosomes (L), and many coated vesicles (small arrows), was closely attached (double arrows) to a severely injured ICC-AP process (ICC*). The injured ICC* process displayed multiple membrane structures (asterisk) and a loss of cytoplasmic content, and was distinguished by the presence of surface caveolae (arrowhead). Simultaneously, a macrophage was partially enclosed (large arrows) by uninjured ICC-AP cytoplasm (ICC) indicating the possibility of functional interaction between the cells, not involving phagocytosis. $\mathrm{m}$, mitochondrion. Original magnifications: $\times 25,000(\mathbf{a}) ; \times 28,900(\mathbf{b}) ; \times 23,750(\mathbf{c})$.

ings, and numerous transport vesicles and lysosomes. ${ }^{16}$ The first days after infection, close contact between ICC-AP and macrophages was not associated with phagocytosis consistent with the fact that these ICC-AP were not injured. Furthermore, in most macrophages, phagosomes did not occur indicating that the macrophages were not involved in phagocytosis during this period. In addition to ICC-AP, macrophages formed frequent close contacts with adjacent smooth muscle cells of both muscle layers. Figure 10a shows a peg-andsocket-like contact between a LM cell and a macrophage process observed 2 days after infection. By day 15 after 


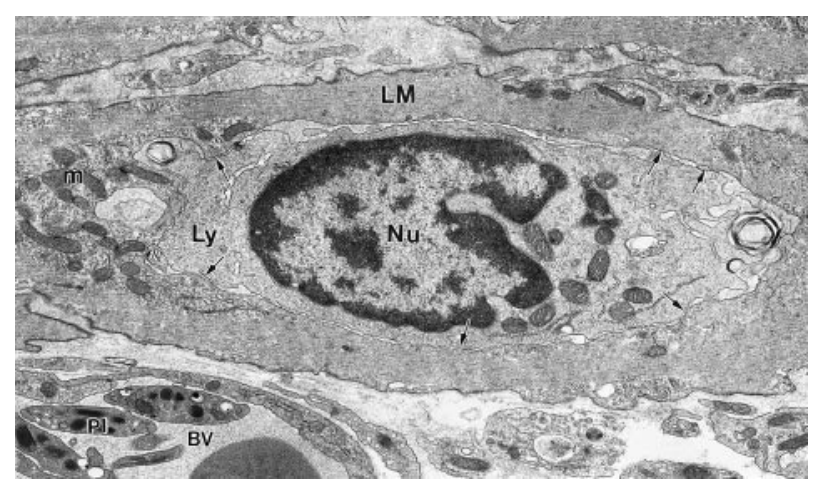

Figure 11. Specialized contact between lymphocyte and smooth muscle cell. At 8 days after infection a lymphocyte (Ly) was enclosed by a LM cell. Note extended close apposition contacts (arrows) between lymphocyte and surrounding smooth muscle cytoplasm indicating the possibility of functional interaction. No injury to the smooth muscle cell was seen. $\mathrm{m}$, mitochondrion; $\mathrm{Nu}$, nucleus of lymphocyte; $\mathrm{BV}$, blood vessel with platelets ( $\mathrm{pl})$. Original magnification, $\times 12,860$

infection, some macrophages containing numerous large phagosomes and lysosomes were now involved in phagocytosis of damaged cellular processes. Figure 10c shows a macrophage containing secondary lysosomes attached to a severely injured ICC-AP process. During this period, many macrophages were found in close association with lymphocytes and occasionally with eosinophils. Between 40 and 60 days after infection, macrophages situated between the two muscle layers and in the subserosal space were distinguished by the presence of large phagosomes, containing residual bodies, indicating their continuing involvement in phagocytosis of debris.

In addition to macrophages, many lymphocytes and a small number of eosinophils started to infiltrate the musculature from 6 days after infection. The majority of lymphocytes were observed at the level of $\mathrm{AP}$, or scattered between smooth muscle cells adjacent to it. Close contacts formed between lymphocytes and smooth muscle cells as illustrated by Figure 11 where a lymphocyte is shown to be enclosed by a LM cell forming extensive close apposition contact with it. Within the AP region, lymphocytes frequently formed close apposition contacts with ICC-AP processes (Figure 12). Lymphocytes were also observed at the deep muscular plexus and in the subserosa. In addition to scattered single immune cells, accumulation of macrophages and lymphocytes was frequently observed between the main muscle layers usually at close proximity to blood vessels where macrophages and lymphocytes formed extensive close contacts with each other. Eosinophils were seen mostly in the $\mathrm{CM}$ layer and between the two main muscle layers (not shown). They did not make special contacts with smooth muscle cells or ICC-AP. Within the AP region eosinophils were mostly observed in close proximity to blood vessels. Mast cells were rarely encountered in the muscle layers and no increase in mast cells was observed during the period of inflammation and recovery.

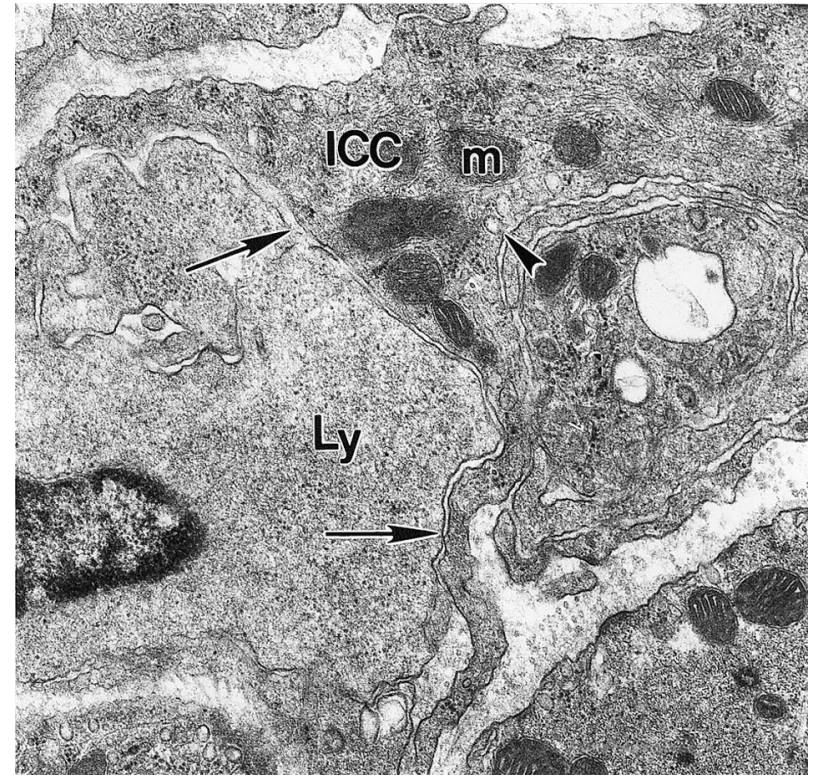

Figure 12. Close apposition contact between lymphocyte and ICC. At 15 days after infection a close apposition (arrows) between a lymphocyte (Ly) and ICC-AP processes (ICC) indicating the possibility of functional interaction between the two cells is seen. Arrowhead indicates ICC caveolae. Original magnification, $\times 21,560$.

\section{Discussion}

The present study reveals that a mucosal infection leads to marked and early ultrastructural changes to ICC-AP associated with AP. In contrast, c-Kit immunohistochemistry failed to identify significant alterations because no ICC-AP loss was occurring and the c-Kit receptor survived the effects of inflammation. The damage to ICC-AP was significant enough to lead to major functional changes. ${ }^{10}$ It is important to note that almost all recent studies into the pathology of ICC exclusively used c-Kit staining. ${ }^{8}$ The present study reveals that significant pathological lesions that have marked physiological consequences can be overlooked when only immunostaining is performed. Because the ultrastructure of human ICC-AP is well described $6,9,14,17-19$, it will be important to include this technique when the pathology of human ICC has to be evaluated.

The present study shows that the ICC-AP (especially the ICC-AP close to the blood vessels) were one of the first cells in the musculature to show structural damage after a mucosal infection. It is important to note that the observed injury to most ICC-AP did not involve all cellular organelles but primarily the cell membrane and filaments. Other structures such as the mitochondria remained the least affected. Any type of injury because of fixation will involve injury to mitochondria, plus the fact that damage was not observed in adjacent cells and control tissue, as well as the fact that most of the injured ICC-AP were close to the dilated blood vessels, ruling out that damage observed was related to fixation. Patchy damage primarily to ICC-AP processes will leave parts of the ICC network undisturbed, which makes slow-wave-driven peristalsis still possible. ${ }^{10}$ Indeed, the present study shows that the general network structure of ICC is still intact. The exis- 
tence of a network structure has clear advantages. When parts of it are damaged, electrical activity may find its way around it. What EM reveals and what immunohistochemistry does not show is that ICC processes are damaged and that contacts between these ICC and smooth muscle cells and nerves are lost.

From day 3 onward, a dramatic change occurred in the ICC-AP as they displayed extensive proliferation of ribosomes and rER, and expansion of Golgi complexes in their cytoplasm. This synthesizing capacity is not only found in the perinuclear space, where normally only a few rER and Golgi complexes are found, but also in the larger processes as well as in the terminal processes where normally no rER nor Golgi complexes are found. An abundance of such terminal processes were found in the AP region 6 to 23 days after infection, where in the early days after infection many damaged processes were found. This indicates a regrowth of the terminal processes. In addition, lymphocytes made specialized contacts with smooth muscle cells and ICC-AP with marked synthetic activity and sometimes were seen to be enclosed by these cells. Importantly, no such intimate contacts were observed between eosinophils and smooth muscle cells or ICC-AP, hence the observed specialized contacts with lymphocytes can not be described as accidental. Such intimate contacts and increased synthetic activity support the concept of immunomodulation of intestinal smooth muscle function ${ }^{20-22}$ and indicate that ICC-AP might be an active participant in the immune process. Cells with a synthetic phenotype diminished in number between days 23 and 40 but even at day 60 after infection they were still present.

The most dominant immune cell involved was the macrophage that invaded both the AP region and the musculature. Macrophages entered the musculature after 24 hours and made close apposition contacts including peg-and-socket-like contacts with ICC-AP and smooth muscle cells. Macrophages were the most prominent immune cell not confined to the areas around blood vessels but distributed throughout the musculature, although a relatively high concentration was observed in the AP area with intimate contacts with the ICC-AP. Macrophages in the muscle layers of uninfected animals are classified as resident macrophages. ${ }^{11,15,23-26}$ Although all other immune cells disappeared from the musculature, many macrophages remained 60 days after infection, now concentrated in the AP region and even within the musculature where there were none before infection. Even after 60 days, the macrophages identified by EM were still activated. Whether or not after a longer time the number of resident, non-activated macrophages increases, remains to be seen.

In the early days after infection, macrophages showed little sign of phagocytic activity, but made specialized contact with uninjured ICC-AP, including peg-and-socket-like junctions. Such ICC-AP showed markedly increased $r E R$, hence it seems that macrophages may be associated with the induction of $r E R$ possibly through secretion of cytokines or growth factors. After day 6 , macrophages showing signs of phagocytic activity were seen associated with injured cells. Recent studies on op/op mice may provide a hypothesis as to the mechanism by which macrophages are involved in tissue injury. Op/op mice have a mutation in the colony-stimulating factor-1 (CSF-1) gene rendering this cytokine nonfunctional. ${ }^{27}$ Op/op mice do not have macrophages in the musculature ${ }^{28}$ except occasionally in the subserosa, and on a $T$. spiralis infection, no macrophages invade the musculature. ${ }^{29}$ This indicates that the macrophages that are associated with ICC before and during infection are CSF-1-dependent macrophages. CSF-1-dependent macrophages are principally involved in cytokine secretion, ${ }^{30}$ and in op/op mice, no production of interleukin- $1 \beta$ within the muscle layer (in contrast to control ${ }^{31}$ ) was observed in response to a Trichinella infection. ${ }^{29}$ Hence it is likely that CSF-1-dependent resident macrophages and CSF-1-dependent-invading macrophages become activated during a $T$. spiralis infection, on which interleukin- $1 \beta$ is released that in turn initiated a cascade of events involving prostaglandins and tumor necrosis factor- $\alpha$, which causes injury to ICC, similar to the development of cholinergic nerve dysfunction that also occurs in this model. ${ }^{29}$ The present study shows that mast cells within the musculature are not players in the immune response to $T$. spiralis.

In several human motility disorders ICC are implicated based on abnormal numbers as observed at the light microscopy level using c-Kit immunohistochemistry but few data are available on the ultrastructural pathology of ICC. ${ }^{9,32}$ Rumessen ${ }^{33}$ examined tissues from patients with advanced ulcerative colitis. He showed that ICC at the colonic submuscular border displayed specific abnormalities, whereas the nearby smooth muscle cells appeared normal. The typical changes found in ICC were: occurrence of multiple secondary lysosomes, the presence of large lipid vacuoles, as well as margination and clumping of intermediate filaments-structural signs of severe cellular injury. No structural signs of recovery of ICC were found. In children with infantile hypertrophic pyloric stenosis, ICC were not present in sections of CM, although there were cells with ultrastructural characteristics of underdeveloped ICC. ${ }^{34}$ Acid-induced inflammation in the dog colon also affected ICC, suggesting that also in the colon, ICC damage may underlie motor abnormalities. ${ }^{35}$ In a study on Hirschsprung's disease, ICC were found to be markedly reduced in number by immunohistochemistry and EM showed that the remaining ICC had normal ultrastructural features. ${ }^{36}$ The present study describes the ultrastructural pathology of ICC associated with AP that serve as pacemaker cells of the small intestine. It is shown that a mucosal infection induces immediate inflammation in the musculature. Within 24 hours, macrophages enter the musculature and ICC-AP processes are structurally damaged. This can be demonstrated ultrastructurally but not by using c-Kit immunohistochemistry. Damage to ICC is correlated with disturbed slow-wave activity and disrupted peristaltic motor patterns. ${ }^{10}$ 


\section{Acknowledgments}

We thank Jean-Marie Vanderwinden for his support in the early stages of this work and Patricia Blennerhassett for her help and support.

\section{References}

1. Ward SM, Burns AJ, Torihashi S, Sanders KM: Mutation of the protooncogene c-kit blocks development of interstitial cells and electrical rhythmicity in murine intestine. J Physiol (Lond) 1994, 480:91-97

2. Huizinga JD, Thuneberg L, Klüppel M, Malysz J, Mikkelsen HB, Bernstein $\mathrm{A}$ : The $\mathrm{W} / \mathrm{kit}$ gene required for interstitial cells of Cajal and for intestinal pacemaker activity. Nature 1995, 373:347-349

3. Der-Silaphet T, Malysz J, Arsenault AL, Hagel S, Huizinga JD: Interstitial cells of Cajal direct normal propulsive contractile activity in the small intestine. Gastroenterology 1998, 114:724-736

4. Thuneberg L: Interstitial cells of Cajal: intestinal pacemaker cells? Adv Anat Embryol Cell Biol 1982, 71:1-130

5. Komuro T, Tokui K, Zhou DS: Identification of the interstitial cells of Cajal. Histol Histopathol 1996, 11:769-786

6. Faussone-Pellegrini MS, Thuneberg L: Guide to the identification of interstitial cells of Cajal. Microsc Res Tech 1999, 47:248-266

7. Maeda H, Yamagata A, Nishikawa S, Yoshinaga K, Kobayashi S, Nishi K: Requirement of c-kit for development of intestinal pacemaker system. Development 1992, 116:369-375

8. Timmermans JP: Interstitial cells of Cajal: is their role in gastrointestinal function in view of therapeutic perspectives underestimated or exaggerated? Folia Morphol (Warsz) 2001, 60:1-9

9. Vanderwinden JM, Rumessen JJ: Interstitial cells of Cajal in human gut and gastrointestinal disease. Microsc Res Tech 1999, 47:344360

10. Der T, Bercik P, Donnelly G, Jackson T, Berezin I, Collins SM, Huizinga JD: Interstitial cells of Cajal and inflammation-induced motor dysfunction in the mouse small intestine. Gastroenterology 2000, 119:1590-1599

11. Mikkelsen HB, Thuneberg L, Wittrup IH: Selective double staining of interstitial cells of Cajal and macrophage-like cells in small intestine by an improved supravital methylene blue technique combined with FITC-dextran uptake. Anat Embryol (Berl) 1988, 178:191-195

12. Castro GA, Fairbairn D: Carbohydrates and lipids in Trichinella spiralis larvae and their utilization in vitro. J Parasitol 1969, 55:51-58

13. Vermillion DL, Collins SM: Increased responsiveness of jejunal longitudinal muscle in Trichinella-infected rats. Am J Physiol 1988, 254: G124-G129

14. Komuro T: Comparative morphology of interstitial cells of Cajal: ultrastructural characterization. Microsc Res Tech 1999, 47:267-285

15. Mikkelsen HB: Macrophages in the external muscle layers of mammalian intestines. Histol Histopathol 1995, 10:719-736

16. Ghadially FN: Ultrastructural pathology of the cell and matrix. Boston, Buttersworth-Heinemann, 1997

17. Rumessen JJ: Identification of interstitial cells of Cajal. Significance for studies of human small intestine and colon. Dan Med Bull 1994, 94:275-293

18. Faussone Pellegrini MS, Pantalone D, Cortesini C: An ultrastructural study of the interstitial cells of Cajal of the human stomach. J Submicrosc Cytol Pathol 1989, 21:439-460
19. Rumessen JJ, Thuneberg L: Interstitial cells of Cajal in human small intestine. Ultrastructural identification and organization between the main smooth muscle layers. Gastroenterology 1991, 100:1417-1431

20. Geboes K, Rutgeerts P, Desmet V: Lymphocyte interactions with smooth muscle cells and nerves. The Effects of Immune Cells and Inflammation on Smooth Muscle and Enteric Nerves. Edited by WJ Snape, SM Collins. Boca Raton, CRC Press, 1990, pp 257-270

21. Hogaboam CM, Snider DP, Collins SM: Activation of T lymphocytes by syngeneic murine intestinal smooth muscle cells. Gastroenterology 1996, 110:1456-1466

22. Vermillion DL, Ernst PB, Collins SM: T-lymphocyte modulation of intestinal muscle function in the Trichinella-infected rat. Gastroenterology 1991, 101:31-38

23. Mikkelsen HB, Rumessen JJ: Characterization of macrophage-like cells in the external layers of human small and large intestine. Cell Tissue Res 1992, 270:273-279

24. Komuro T: Three-dimensional observation of the fibroblast-like cells associated with the rat myenteric plexus, with special reference to the interstitial cells of Cajal. Cell Tissue Res 1989, 255:343-351

25. Eskandari MK, Kalff JC, Billiar TR, Lee KK, Bauer AJ: Lipopolysaccharide activates the muscularis macrophage network and suppresses circular smooth muscle activity. Am J Physiol 1997, 273: G727-G734

26. Mikkelsen HB, Thuneberg L, Rumessen JJ, Thorball N: Macrophagelike cells in the muscularis externa of mouse small intestine. Anat Rec 1985, 213:77-86

27. Marks Jr SC, Lane PW: Osteopetrosis, a new recessive skeletal mutation on chromosome 12 of the mouse. J Hered 1976, 67:11-18

28. Mikkelsen HB, Thuneberg L: Op/op mice defective in production of functional colony-stimulating factor-1 lack macrophages in muscularis externa of the small intestine. Cell Tissue Res 1999, 295:485-493

29. Galeazzi F, Lovato P, Blennerhassett PA, Haapala EM, Vallance BA, Collins SM: Neural change in Trichinella-infected mice is MHC ॥ independent and involves M-CSF-derived macrophages. Am J Physiol 2001, 281:G151-G158

30. Wiktor-Jedrzejczak W, Ansari AA, Szperl M, Urbanowska E: Distinct in vivo functions of two macrophage subpopulations as evidenced by studies using macrophage-deficient op/op mouse. Eur J Immunol 1992, 22:1951-1954

31. Collins SM, Hurst SM, Main C, Stanley E, Khan I, Blennerhassett P, Swain M: Effect of inflammation of enteric nerves. Cytokine-induced changes in neurotransmitter content and release. Ann N Y Acad Sci 1992, 664:415-424

32. Huizinga JD: Neural injury, repair, and adaptation in the GI tract. IV. Pathophysiology of gastrointestinal motility related to interstitial cells of Cajal. Am J Physiol 1998, 275:G381-G386

33. Rumessen JJ: Ultrastructure of interstitial cells of Cajal at the colonic submuscular border in patients with ulcerative colitis. Gastroenterology 1996, 111:1447-1455

34. Langer JC, Berezin I, Daniel EE: Hypertrophic pyloric stenosis: ultrastructural abnormalities of enteric nerves and the interstitial cells of Cajal. J Pediatr Surg 1995, 30:1535-1543

35. Lu G, Qian X, Berezin I, Telford GL, Huizinga JD, Sarna SK: Inflammation modulates in vitro colonic myoelectric and contractile activity and interstitial cells of Cajal. Am J Physiol 1997, 273: G1233-G1245

36. Vanderwinden JM, Rumessen JJ, Liu H, Descamps D, De Laet MH, Vanderhaeghen JJ: Interstitial cells of Cajal in human colon and in Hirschsprung's disease. Gastroenterology 1996, 111:901-910 